\title{
Production of $\omega$-Haloesters from Alkyl Halides by Micrococcus cerificans
}

\author{
By P. E. KOLATTUKUDY AND L. HANKIN \\ Department of Biochemistry, The Connecticut Agricultural Experiment \\ Station, New Haven, Connecticut 06504, U.S.A.
}

(Accepted for publication I4 June I968)

\begin{abstract}
SUMMARY
Micrococcus cerificans grows with $n$-alkyl chlorides and bromides containing 16 to 20 carbon atoms as the sole source of carbon and forms waxy esters. The esters produced from $n$-Hexadecyl chloride were identified to be 16-chlorohexadecyl-I6-chlorohexadecanoate $(74 \%)$ and I6-chlorohexadecylhexadecanoate $(23 \%)$. More than $80 \%$ of the fatty acids of the more polar cellular lipids also contained chlorine at the $\omega$-carbon. These results show that the mechanism of utilization of alkyl halides by this organism is similar to that of alkanes and the initial attack is specifically at the non-halogenated methyl carbon.
\end{abstract}

\section{INTRODUCTION}

Many species of micro-organisms oxidize alkanes (McKenna \& Kallio, I965) and apparently a portion of the hydrocarbons that reach the soil from the cuticular lipids of plants is degraded by micro-organisms (Hankin \& Kolattukudy, I968). Micrococcus cerificans, an organism isolated from soil, oxidizes alkanes of medium chain length, $C_{11}$ to $C_{26}$ (Finnerty, Hawtrey \& Kallio, I962) as well as very long chains such as $n$-nonacosane (Hankin \& Kolattukudy, 1968). Oxidative attack by this organism on the medium-length paraffins starts from the terminal methyl group, giving primary alcohols as the first stable product. Since production of the alcohol is more rapid than its further oxidative degradation, it undergoes esterification with fatty aids and the resulting waxy ester is excreted (Stewart et al. 1959). When the hydrocarbon contains a double-bond at one end, the bacterium attacks the other end, thus giving the $\omega$-unsaturated alcohol (Stewart et al. 1960). In the present report it is shown that $M$. cerificans can readily grow on alkyl halides by oxidizing the molecule primarily from the non-halogenated end. The bacterium oxidized alkyl halides to $\omega$-halo fatty alcohols and fatty acids, which in turn were esterified to produce the dihalo waxy esters. Since $\omega$-haloacids and alcohols are important intermediates in synthetic organic chemistry, the bacterial production of such intermediates might be of potential use.

\section{METHODS}

Organism. Micrococcus cerificans (kindly provided by Dr R. E. Kallio, University of Illinois, Urbana), was maintained as a stock culture as previously described (Hankin \& Kolattukudy, I968).

Substrates. $n$-Hexadecylchloride and bromide, $n$-octadecylchloride and bromide, and $n$-eicosylchloride were obtained from Humphrey Chemical Company, North 
Haven, Conn., U.S.A. The I,I6-dibromohexadecane was obtained from $\mathrm{K}$ and $\mathrm{K}$ Laboratories, Plainview, N.J., U.S.A.

Media. The basal mineral medium used was described by Hankin \& Kolattukudy (1968). All test substrates were added directly to the mineral medium, which was sterilized by autoclaving. Ultrasonic treatment (Biosonik II, Will Corp., Rochester, N.Y., at $90 \%$ of maximum output for 10 min.) was used to disperse I, I6-dibromohexadecane and $n$-eicosylhexadecane,

Growth studies. Cultures for growth measurements on different substrates were made in $250 \mathrm{ml}$. Erlenmeyer flasks containing $25 \mathrm{ml}$. mineral medium $+0.5 \%(\mathrm{w} / \mathrm{v})$ alkyl halide. Rate of growth was measured by a plating procedure on Trypticase Soy Agar (Baltimore Biological Laboratories, Baltimore, Maryland). For all tests, the organism was grown in shake culture in a water bath at $30^{\circ}$.

Detection of ester production. At the end of the growth tests the entire culture was mixed with a sufficient amount of $2+I$ by vol. chloroform + methanol mixture to give a single liquid phase and allowed to stand for at least $18 \mathrm{hr}$. Total lipids were isolated by the method of Folch, Lees \& Sloane-Stanley (I957), and chromatographed on thin-layer plates with benzene as the developing solvent. Lipids were located by a sulphuric acid + dichromate charring method.

Isolation and fractionation of lipids. To obtain sufficient material for identification purposes, $500 \mathrm{ml}$. cultures were used. With such large amounts a longer incubation time was necessary to reach peak growth, presumably because aeration was less efficient with the larger volume. After $72 \mathrm{hr}$ of incubation the bacteria were collected by centrifugation. Although the supernatant fluid contained some waxy esters, it was more convenient to isolate them from the bacterial mass. This does not imply that the esters were within the organisms. The wet bacterial mass was stirred with $400 \mathrm{ml}$. of a $2+$ I mixture $(\mathrm{v} / \mathrm{v})$ of chloroform + methanol at $45^{\circ}$ for 4 to $5 \mathrm{hr}$. Total lipids were isolated from this mixture by the method of Folch et al. (1957). The chloroform was evaporated under reduced pressure, and the residue was dissolved in boiling $95 \%(\mathrm{v} / \mathrm{v})$ ethanol in water and cooled. The crystalline material was collected and recrystallized twice from $95 \%(\mathrm{v} / \mathrm{v})$ ethanol in water. The product at this stage of purification usually melted at $49-50^{\circ}$. Preparative thin-layer chromatography followed by recrystallization from $95 \%(\mathrm{v} / \mathrm{v})$ ethanol gave a product melting at $50-5 \mathrm{I}^{\circ}$. This ester fraction was used for the structural analysis.

Since a substantial amount of unbroken bacteria was found after the above treatment, the bacterial residue was freeze-dried and then refluxed with the chloroform + methanol mixture for $6 \mathrm{hr}$, under nitrogen. The lipids thus extracted were pooled with the mother liquors from the crystallizations described above and were designated 'total lipids'.

Column chromatography. The total lipids were applied to a column $(2 \cdot 5+55 \mathrm{~cm}$.) containing SilicAR CC-4, I00-200 mesh (Mallinckrodt Chemical Works, St Louis, Mo., U.S.A.). The unused alkyl halides and the relatively non-polar lipids such as waxy esters, were removed by elution with $500 \mathrm{ml}$. benzene. The more polar lipids were then eluted with methanol. This fraction is referred to as 'cell lipids'.

Preparation of methyl esters. The cell-lipid fraction isolated by column chromatography was refluxed under nitrogen with $14 \%$ of $\mathrm{BF}_{3}$ in methanol (Analabs, Hamden, Conn., U.S.A.) for $24 \mathrm{hr}$. Water was added and the lipids extracted with chloroform. Methyl esters were isolated by thin-layer chromatography. 
Reduction of waxy esters with lithium aluminium hydride. To an ethereal solution of waxy ester, several fold excess of lithium aluminium hydride was added and stirred for $30 \mathrm{~min}$. at room temperature. These mild conditions were used to minimize substitution of the chlorine with hydrogen (Johnson, Blizzard \& Carhart, I948). After decomposing the excess of reagent with water, the products were extracted with ether. The alcohols were then purified by thin-layer chromatography.

Thin-layer chromatography. Silica gel G plates 0.5 or $1.0 \mathrm{~mm}$. thick for preparative purposes and $0.3 \mathrm{~m}$. thick for analytical purposes were used (Kolattukudy, 1965). The waxy esters and methyl esters were chromatographed with benzene as the developing solvent (Kolattukudy, 1965, 1966). The fatty acids and fatty alcohols were chromatographed with a mixture of hexane +diethyl ether + formic acid $(40+10+1$, by vol.; Kolattukudy, 1967a).

Gas-liquid chromatography. A Perkin Elmer 810 Gas Chromatograph with flame ionization detector was used. Fatty alcohols, methyl esters of fatty acids and waxy esters were analyzed on a $5 \%$ silicone gum rubber (SE 30) column. Methyl esters were also analyzed on a $15 \%$ stabilized diethylene glycol succinate column. Authentic samples of methyl esters of fatty acids (Analabs, Hamden, Conn.) and fatty alcohols (Humphrey Chemical Co., North Haven, Conn.) were used as standards. The waxy esters used as standards were prepared as previously described (Kolattukudy, 1967b) Conditions for gas-liquid chromatography are given with the legends to the figures.

Infrared and mass spectra. Infrared spectra were obtained on thin films of materia with a Perkin Elmer Model 21 Infrared Spectrophotometer (courtesy of R. A. Botsford of this Station).

Mass spectra was obtained with an MS Mass Spectrometer at $70 \mathrm{eV}$. with $250^{\circ}$ as the source temperature.

\section{RESULTS}

\section{Growth of Micrococcus cerificans on alkyl halides}

Growth of Micrococcus cerificans with various alkyl halides as the sole source of carbon is depicted in Fig. I. The organism grew readily on $\mathrm{C}_{16}, \mathrm{C}_{18}$, and $\mathrm{C}_{20}$ alkyl chlorides, and on $\mathrm{C}_{16}$ and $\mathrm{C}_{18}$ alkyl bromides. In all instances maximum growth was obtained at about $36 \mathrm{hr}$, and the growth on the alkyl halides was comparable to that observed with the corresponding alkanes. The effect of substituting halogens on both ends of the alkane on the growth of the organism was tested by providing I, I6-dibromohexadecane as the sole carbon source; with this the organism did not grow.

\section{Waxy ester production from aklyl halides}

Lipids isolated from the cultures at the end of the growth period were analysed by thin-layer chromatography on silica gel $\mathrm{G}$ with benzene as the solvent. Three major spots were detected in all cases. The spot nearest to the solvent front $\left(\mathrm{R}_{F}, c .0 .85\right)$ corresponded to unused alkyl halide. A second spot had an $R_{F}(c .0 \cdot 70)$ identical to that of waxy esters. The more polar lipids remained at the origin. The organism produced less ester from bromides than from the corresponding chlorides. As the chain length increased from $\mathrm{C}_{16}$ to $\mathrm{C}_{20}$, ester production decreased. Thus, more esters were produced from $\mathbf{C}_{\mathbf{1 6}}$ chloride than from the other substrates. 


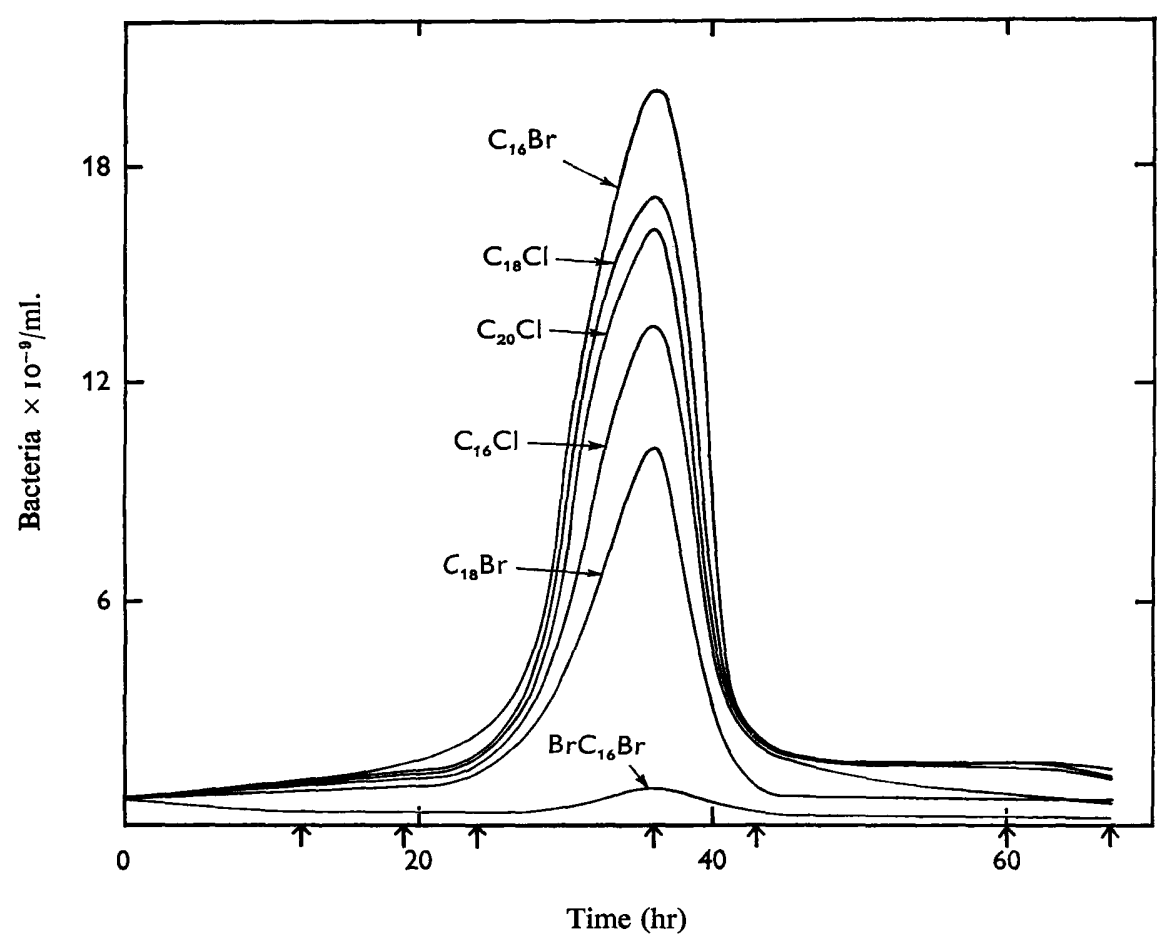

Fig. I. Growth of Micrococcus cerificans on $n$-hexadecylchloride $\left(\mathrm{C}_{16} \mathrm{Cl}\right)$ and bromide $\left(\mathrm{C}_{16} \mathrm{Br}\right)$, $n$-octadecylchloride $\left(\mathrm{C}_{18} \mathrm{Cl}\right)$ and bromide $\left(\mathrm{C}_{18} \mathrm{Br}\right)$, n-eicosylchloride $\left(\mathrm{C}_{20} \mathrm{Cl}\right)$ and 1,16 -dibromohexadecane $\left(\mathrm{BrC}_{18} \mathrm{Br}\right)$. The arrows on the abscissa indicate times at which growth was measured. The amount of growth at the peak varied, apparently because of the intervals at which growth was measured.

\section{Structure of waxy esters}

Since the $n$-hexadecylchloride gave more ester than the other halides it was used to produce esters for structural studies. It is assumed that similar products were formed from the other alkyl halides. The crystalline ester fraction obtained as described under Methods had a melting point of $50-51^{\circ}$. Further preparative thin-layer chromatography and subsequent recrystallization did not alter the melting point. The esters produced by Micrococcus cerificans from $n$-hexadecane melted at $46-48^{\circ}$ (Stewart $e t$ al. 1959). The higher melting point of the ester produced from $n$-hexadecylchloride suggested the presence of chlorine atoms in the ester.

The infrared spectrum (Fig. 2) showed the absorption expected of long alkane chains, absorptions at $1735 \mathrm{~cm} .^{-1}$ and $1175 \mathrm{~cm} .^{-1}$ characteristic of an ester function as well as at $725 \mathrm{~cm}^{-1}$ and $737 \mathrm{~cm}^{-1}$ indicative of the $\mathrm{C}-\mathrm{Cl}$ bond.

Gas-liquid chromatography of the wax esters on an SE-30 column showed that there were three esters in the crystalline waxy ester fraction, representing 74,23 and $3 \%$ of the total mass and marked A, B, C, respectively on Fig. 3. Peak $\mathrm{C}$ had a retention time equal to that of cetyl palmitate. Peaks $B$ and $A$ had retention times corresponding to $\mathrm{C}_{34 \cdot 5}$ and $\mathrm{C}_{37}$ esters, respectively. Since the mass of one chlorine atom is equivalent to that of 2.5 methylene groups, peak $B$ probably represented $C_{32}$ ester with one chlorine atom, and peak $\mathrm{A} \mathrm{C}_{32}$ ester containing two chlorine atoms. 
Treatment of the ester fraction with lithium aluminium hydride gave a product on thin-layer chromatography with an $\mathbf{R}_{F}$ corresponding to fatty alcohol. This product when isolated from the thin-layer plate and subjected to gas-liquid chromatographic analysis on an SE-30 column gave two major peaks: one peak with a retention time of $\mathrm{C}_{16}$ alcohol (about $20 \%$ of the mass); the other peak (about $80 \%$ of the mass) with a retention time corresponding to $\mathrm{C}_{18 \cdot 5}$ which probably represented the $\mathrm{C}_{16}$ alcohol containing one chlorine atom.

Frequency $\left(\mathrm{cm} .^{-1}\right)$

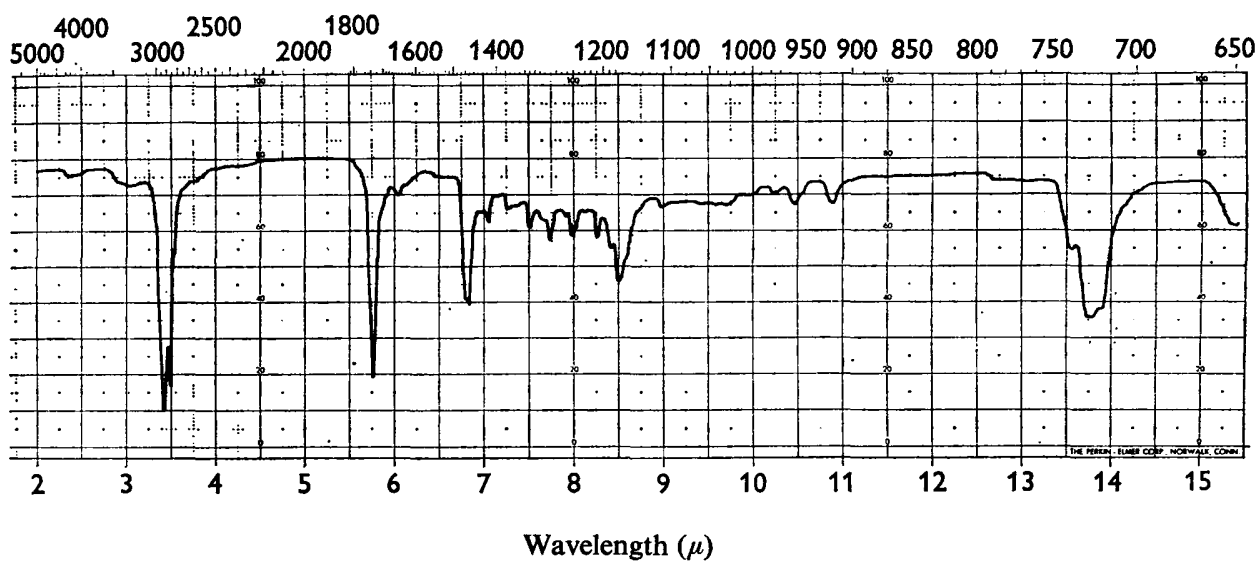

Fig. 2. Infrared spectrum of waxy esters produced by Micrococcus cerificans from $n$-hexadecyl chloride.

Table I. Measurement of mass of the molecular ions from the dihalo ester

\begin{tabular}{lcc}
\multicolumn{1}{c}{ Species } & Measured mass & Calculated mass \\
$\mathrm{C}_{32} \mathrm{H}_{62} \mathrm{O}_{2} \mathrm{Cl}_{2}$ & $548 \cdot 40968$ & $548 \cdot 4 \mathrm{I} 30$ \\
$\mathrm{C}_{31} \mathrm{C}^{13} \mathrm{H}_{62} \mathrm{O}_{2} \mathrm{Cl}_{2}$ & $549 \cdot 41466$ & $549 \cdot 4164$ \\
$\mathrm{C}_{32} \mathrm{H}_{62} \mathrm{O}_{2} \mathrm{Cl}^{35} \mathrm{Cl}^{37}$ & $550 \cdot 40877$ & $550 \cdot 4 \mathrm{IO0}$ \\
$\mathrm{C}_{31} \mathrm{C}^{13} \mathrm{H}_{62} \mathrm{O}_{2} \mathrm{Cl}^{35} \mathrm{Cl}^{37}$ & $55 \mathrm{I} \cdot 4 \mathrm{I} 375$ & $55 \mathrm{I} \cdot 4 \mathrm{I} 34$
\end{tabular}

Mass spectral analysis. The molecular ion at 548 corresponded to the structure $\mathrm{ClC}_{15} \mathrm{H}_{30} \mathrm{COOCH}_{2} \mathrm{C}_{15} \mathrm{H}_{30} \mathrm{Cl}$. Mass measurements of the various species of the molecular ion by a peak-matching technique with perfluorokerosene (Table I), agreed with the proposed structure. The relative abundance of ions at 548,550 , and $55^{2}$ confirmed the presence of two chlorine atoms in this ion. As expected from such an ester (RCOOR') there were dominant ion intensities at $29 \mathrm{I}$ corresponding to the $\mathrm{RCOOH}_{2}{ }^{+}$, and at 258 corresponding to $\left(\mathrm{R}^{\prime}-\mathrm{H}\right)^{+}$. The other characteristic ions expected from the proposed structure were also present as shown in Table 2. The presence of the chlorine atoms in the fragment ions was confirmed by the characteristic isotopic ratios due to chlorine. As indicated by the gas-liquid chromatographic analysis, the ester contained a monohalo ester giving rise to the ion at 514. The chlorine atom contained in this ion was expected to be on the $\omega$ carbon atom of the alcohol. Confirming this prediction there were fragment ions derived from the non-halo acyl moiety, but ions indicating a non-halo alcohol moiety were hardly detectable. In accordance with the assignment of the minor component $(3 \%)$ of the ester as a non-halo ester there was 
an ion at 480 which was most likely the molecular ion from etyl palmitate. Thus the mass spectral analysis confirmed the conclusions drawn about the structure of the esters from the other analyses described above.

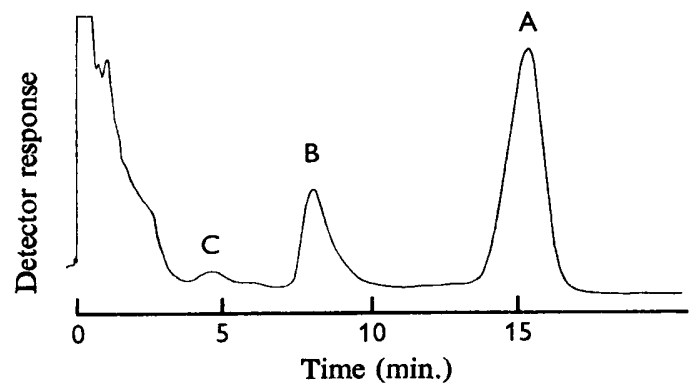

Fig. 3

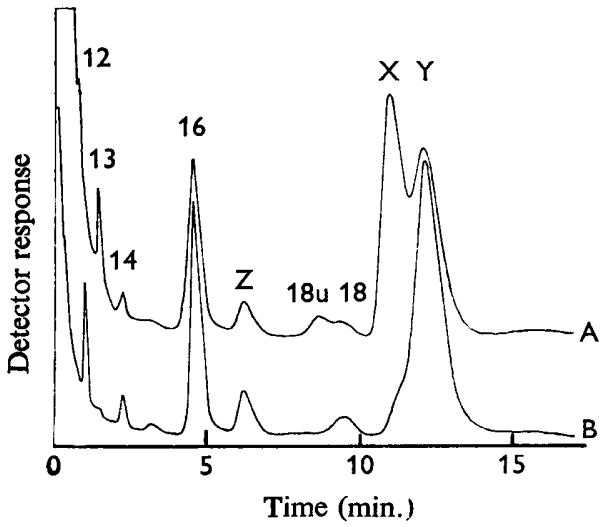

Fig. 4

Fig. 3. Gas-liquid chromatogram of waxy esters produced by Micrococcus cerificans from $n$-hexadecyl chloride. Column: $5 \%$ SE 30 on Anakrom SD, $4 \mathrm{ft} ., 0.25$ in o.d. at $305^{\circ}$ with carrier-gas argon $75 \mathrm{ml} . / \mathrm{min}$. A, $\omega$-chlorohexadecyl $\omega$-chlorohexadecanoate; B, $\omega$-chlorohexadecyl hexadecanoate; $\mathrm{C}$, hexadecyl hexadecanoate.

Fig. 4. Gas-liquid chromatogram of methyl esters of fatty acids of cell lipids isolated from Micrococcus cerificans grown on $n$-hexadecyl chloride. Column same as in Fig. 3 at $212^{\circ}$ with carrier-gas argon at $80 \mathrm{ml}$. $/ \mathrm{min}$. The fatty acids are identified by the number of carbon atoms; $\mathrm{u}$ represents unsaturation; $\mathrm{Y}, \omega$-chlorohexadecanoate; $\mathrm{X}$, unsaturated $\omega$-chlorohexadecanoate; Z, $\omega$-chlorotetradecanoate. A, before bromination; B, after bromination.

Table 2. The major ions in the mass spectrum of the waxy ester

\begin{tabular}{cl} 
Mass/charge & \multicolumn{1}{c}{ Probable structure of the ion } \\
548 & {$\left[\mathrm{ClC}_{15} \mathrm{H}_{30} \mathrm{COOCH}_{2} \mathrm{C}_{15} \mathrm{H}_{30} \mathrm{Cl}\right]+$} \\
$5 \mathrm{I} 4$ & {$\left[\mathrm{C}_{15} \mathrm{H}_{31} \mathrm{COOCH}_{2} \mathrm{C}_{15} \mathrm{H}_{30} \mathrm{Cl}\right]^{+}$} \\
480 & {$\left[\mathrm{C}_{15} \mathrm{H}_{31} \mathrm{COOCH}_{2} \mathrm{COCH}_{15} \mathrm{H}_{31}\right]^{+}$} \\
$33 \mathrm{I}$ & $\mathrm{CH}_{2}: \mathrm{CHC}\left(: \mathrm{OH}^{+} \mathrm{OCH}_{2} \mathrm{C}_{15} \mathrm{H}_{30} \mathrm{Cl}\right.$ \\
318 & $\left.\mathrm{CH}_{2}: \mathrm{C}^{+} \mathrm{OH}\right) \mathrm{CH}_{2} \mathrm{C}_{15} \mathrm{H}_{30} \mathrm{Cl}$ \\
303 & $\mathrm{ClC}_{15} \mathrm{H}_{30} \mathrm{CH}_{2} \mathrm{OCO}^{+}$ \\
$29 \mathrm{I}$ & $\mathrm{ClC}_{15} \mathrm{H}_{30} \mathrm{COOH}_{2}^{+}$ \\
290 & $\mathrm{ClC}_{15} \mathrm{H}_{30} \mathrm{COOH}^{+}$ \\
273 & $\mathrm{ClC}_{15} \mathrm{H}_{30} \mathrm{CO}^{+}$ \\
258 & $\mathrm{ClC}_{16} \mathrm{H}_{31}^{+}$ \\
257 & $\mathrm{ClC}_{16} \mathrm{H}_{30}^{+}$
\end{tabular}

\section{Cellular lipids}

The gas-liquid chromatographic pattern of the methyl esters prepared by transesterifying the cell lipids with methanol containing $\mathrm{I}_{4} \% \mathrm{BF}_{3}$ is shown in Fig. 4, tracing A. About $80 \%$ of the mass was represented by two peaks of approximately equal size, marked $X$ and $Y$. Peak $Y$ had a retention time equivalent to $C_{18 \cdot 5}$ and peak $X$ corresponded to unsaturated $\mathrm{C}_{18 \cdot 5}$. The other major peak ( ${ }_{13} .6 \%$ ) corresponded to $\mathrm{C}_{16}$ and the usual fatty acids $\mathrm{C}_{12}(\mathrm{I} \%), \mathrm{C}_{14}(0.6 \%), \mathrm{C}_{18}(\mathrm{I} \cdot 7 \%)$ and unsaturated $\mathrm{C}_{18}$ $(2 \cdot 3 \%)$ were also found in smaller quantities. Small quantities $(3.4 \%)$ of an acid corresponding to $\mathrm{C}_{\mathbf{1 6 . 5}}$ was also detected. To confirm these assignments, the methyl 
ester fraction was treated with bromine and rechromatographed (Fig. 4, tracing B). The peaks assigned to the unsaturated fatty acid, $\mathrm{C}_{18 \mathrm{u}}$ and $\mathrm{X}$, were virtually eliminated by the bromine treatment in accordance with the identification described above. Peak $Y$, corresponding to $C_{18 \cdot 5}$, must be due to the methyl ester of I6-chloropalmitic acid, because the mass of one chlorine atom is equivalent to that of 2.5 methylene groups. Therefore $X$ represented unsaturated 16-chloropalmitic acid. By the same reasoning peak $Z$ was identified as the methyl ester of $\omega$-chlorotetradecanoic acid. When the same samples were analysed on a diethyleneglycol succinate column, the two major peaks of approximately equal size, represented by saturated and unsaturated chloropalmitic acid, had retention times 5.5 and 6.5 times that of $\mathrm{C}_{16}$ acid respectively as expected from the added mass and polarity introduced by the chlorine atom. Bromine treatment and rechromatography on this column confirmed the presence of unsaturation.

\section{DISCUSSION}

Since the organism grew just as readily on the alkyl halides as on the corresponding alkanes, the organism may be able to attack the terminal carbon irrespective of the atoms attached to it. Alternatively, it may attack specifically the non-halogenated end or the alkyl halides are metabolized by an altogether different mechanism. However, 1,16-dibromohexadecane failed to support growth of the organism indicating its inability to attack carbon atoms which bear a halogen. Thus the specificity of the initial oxidation is for a methyl group.

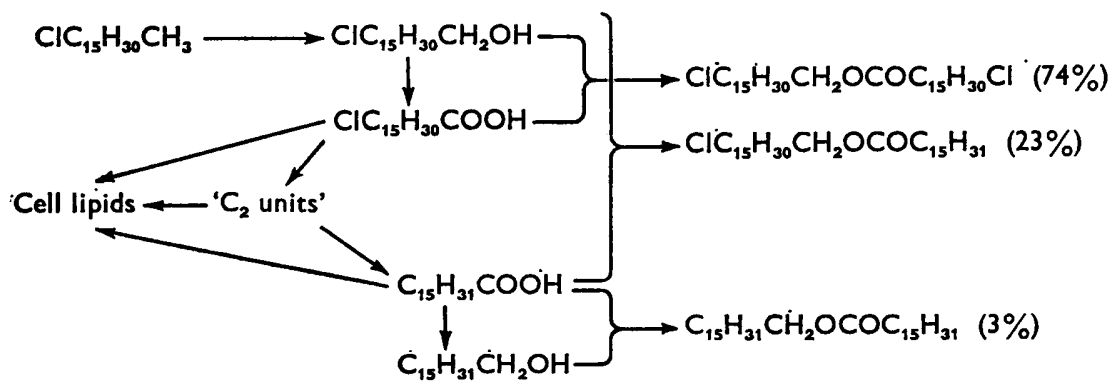

Fig. 5. Proposed metabolic fate of $n$-hexadecyl chloride in Micrococcus cerificans.

The formation of waxy esters is very similar to that observed with alkanes (Stewart et al. 1959; Stewart \& Kallio, 1959), and suggests that the alkyl halide is oxidized in a manner similar to that described for paraffins (Stewart et al. 1959; Baptist, Gholson \& Coon, 1963; Gholson, Baptist \& Coon, 1963). From the structure of the esters produced it is clear that the bacterium attacked specifically the non-halogenated end and produced the $\omega$-haloalcohol which in turn must have undergonefurther oxidation to the $\omega$-haloacid. The acid and alcohol were subsequently esterified to give the major dihalowaxy ester (Fig. 5).

From the structure of the esters produced by the organism from various alkanes (Stewart \& Kallio, 1959) it appears that the saturated fatty acid pool of the organism takes part in esterifying the excess fatty alcohol produced by the alkane oxidation. Thus the fatty alcohol of the ester usually contains the intact carbon chain of the alkane, but the acids always reflect the composition of the general saturated fatty-acid 
pool. While growing on the alkyl halides, Micrococcus cerificans probably produced nonhalogenated $\mathrm{C}_{16}$ acid by de novo synthesis although the major source of fatty acids would be the direct oxidation on the non-halogenated end of the alkyl halides. Thus, the monohalo ester is probably derived from the halo alcohol and the non-halo fatty acids produced by the organism by de novo synthesis. Oxidative attack on some of the halogenated carbons could also produce the non-halogenated fatty acids. However lack of growth on I,I6-dibromohexadecane makes this an unlikely possibility.

The ratio of halo acids to nonhalo acids in the waxy esters was $3: 1$. The same ratio was found for saturated halo acids to saturated non-halo acids of the cell lipids. This observation strongly supports the contention that the saturated fatty acid pool of the organism takes part in the esterification process.

The organism can apparently perform all its biochemical and structural functions with the $\omega$-halo acids instead of the usual fatty acids. It is obvious that even the unsaturated fatty acids could have a halogen on the $\omega$-end without impairing their usual functions in the cell because the major unsaturated fatty acid in the cell was halo $\mathrm{C}_{16}$ acid.

Under the conditions of growth used in this study about $80 \%$ of all the fatty chains produced by the organism from hexadecyl chloride contained chlorine atoms on the $\omega$-carbon atoms. Thus, total lipids could be a convenient source for $\omega$-halo acids and these acids are extremely useful as intermediates in many syntheses. It may be possible to alter growth conditions of the organism so as to obtain a profitable yield of the halo acids. For example, the organism may readily oxidize alkyl halides while growing on inexpensive and readily obtainable media.

We are grateful to Drs W. J. McMurray and S. R. Lipsky, Yale Medical School, for the mass spectral analysis and thank John Marcucci for technical assistance and Katherine Clark for preparation of the figures.

\section{REFERENCES}

Baptist, J. N., Gholson, R. K. \& Coon, M. J. (1963). Hydrocarbon oxidation by a bacterial enzyme system. I. Products of octane oxidation. Biochim. biophys. Acta 69, 40.

Finnerty, W. R., Hawtrey, E. \& Kallio, R. E. (I962). Alkane-oxidizing micrococci. Z. Allgem. Microbiol. 2, 169.

Folch, J., Lees, M. \& Sloane-Stanley, G. H. (1957). A simple method for the isolation and purification of total lipids from animal tissues. J. biol. Chem. 226, 497.

Gholson, R. K., BAPTist, J. N. \& Coon, M. J. (1963). Hydrocarbon oxidation by a bacterial enzyme system. II. Cofactor requirements for octanol formation from octane. Biochemistry 2, 155.

Hankin, L. \& KolatTukudy, P. E. (I968). Metabolism of a plant wax paraffin ( $n$-nonacosane) by a soil bacterium (Micrococcus cerificans). J. gen. Microbiol. 51, 457.

Johnson, J. R., Blizzard, R. H. \& CARhaRT, H. W. (I948). Hydrogenolysis of alkyl halides by lithium aluminium hydride. J. Am. chem. Soc. 7o, 3664.

KollatTuKudy, P. E. (1965). Biosynthesis of wax in Brassica oleracea. Biochemistry 4, 1844.

Kollattukudy, P. E. (1966). Biosynthesis of wax in Brassica oleracea. Relation of fatty acids to wax. Biochemistry 5, 2265.

Kolattukudy, P. E. (1967a). Biosynthesis of paraffins in Brassica oleracea: fatty acid elongationdecarboxylation as a plausible pathway. Phytochemistry 6, 963 .

Kolatrukudy, P. E. (1967 b). Mechanisms of synthesis of waxy esters in broccoli (Brassica oleracea). Biochemistry 6, 2705.

MCKenNA, E. J. \& Kallio, R. E. (1965). The biology of hydrocarbons. A. Rev. Microbiol. 19, 183. 
StewarT, J. R. \& Kallio, R. E. (1959). Bacterial hydrocarbon oxidation. II. Ester formation from alkanes. J. Bact. 78, 726.

Stewart, J. R., Finnerty, W. R., Kallio, R. E. \& Stevenson, D. P. (1960). Esters from bacterial oxidation of olefins. Science., N.Y. 132, 1254.

Stewart, J. R., Kallio, R. E., Stevenson, D. P., Jones, A. J. \& Schissler, D. O. (1959). Bacterial hydrocarbon oxidation. I. Oxidation of $n$-hexadecane by a gram-negative coccus. J. Bact. 78, 44I. 